Sociology in Practice for Health Care Professionals 



\section{Sociology in Practice for Health Care Professionals}

Ron Iphofen

and

Fiona Poland

Consultant editor: Jo Campling

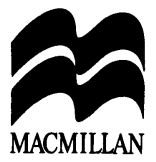




\section{(C) Ron Iphofen and Fiona Poland 1998}

All rights reserved. No reproduction, copy or transmission of this publication may be made without written permission.

No paragraph of this publication may be reproduced, copied or transmitted save with written permission or in accordance with the provisions of the Copyright, Designs and Patents Act 1988, or under the terms of any licence permitting limited copying issued by the Copyright Licensing Agency, 90 Tottenham Court Road, London W1P 9HE.

Any person who does any unauthorised act in relation to this publication may be liable to criminal prosecution and civil claims for damages.

The authors have asserted their rights to be identified as the authors of this work in accordance with the Copyright, Designs and Patents Act 1988.

First published 1998 by MACMILLAN PRESS LTD

Houndmills, Basingstoke, Hampshire RG21 6XS

and London

Companies and representatives

throughout the world

ISBN 978-0-333-64576-5

ISBN 978-1-349-13879-1 (eBook)

DOI 10.1007/978-1-349-13879-1

A catalogue record for this book is available

from the British Library.

This book is printed on paper suitable for recycling and made from fully managed and sustained forest sources.

$\begin{array}{llllllllll}10 & 9 & 8 & 7 & 6 & 5 & 4 & 3 & 2 & 1\end{array}$

$\begin{array}{llllllllll}07 & 06 & 05 & 04 & 03 & 02 & 01 & 00 & 99 & 98\end{array}$

Editing and origination by Aardvark Editorial, Mendham, Suffolk 


\section{Contents}

Preface vii

Acknowledgements $\mathrm{x}$

1 The Nature of Sociology: Explanations and Applications 1

2 The Power to Care 18

3 Learning to Care: A Lifetime of Socialisation 32

4 The Basis of Informal Care: Families and Households 54

5 Healthy Learning $\quad 67$

6 Working for Health 87

7 Equal and Unequal Opportunities 109

8 Inherited Health 130

9 Natural Carers: Sex and Gender 144

10 Common and Uncommon Cultures 164

11 Beliefs, Moralities and Ideologies of Care 180

12 Controlling Conditions 194

13 The Costs of 'Free' Time 214

14 Welfare, III-fare, How Fair? 234

15 Modelling Health Care Sociologically 246

References 254

Index 261 



\section{Preface: How To Use This Book}

One of our reasons for writing this book was to offer an alternative to the more academic introductions to the discipline of sociology. We are assuming that you, our readers, are health care professionals or students who need to use sociology to improve the quality of the care that you give. We hope you are reading the book to broaden your knowledge of your clients and of yourselves. We offer you routes to reflect on action from a sociological viewpoint.

The emphasis of this book is on showing how, starting from your own personal situation, you can begin to locate and use resources which support health and caring. We are also concerned to analyse the constraints on health and care work across a range of social settings. In focusing on the practical experience of health care professionals we look at the exercise of power and oppression within informal and formal care settings. We look at the inequalities which underlie the everyday lives of those working as partners in different kinds of health care encounters: the professional, the carer and the cared-for. We want to highlight the importance of everyday ways of coming to know about health settings and issues.

Small sections of the text are highlighted in bold - like this. By doing this we hope to draw your attention to issues and concepts which we believe are particularly important. Next to each section of bold text there will be an explanation or comment which clarifies its importance. The ideas we present are cumulative so that we do not recommend reading chapters out of context. We are trying to build your expertise with the means and methods of sociological analysis which are of value in health care practice. For example, fully understanding what we say about health policy in Chapter 14 requires understanding the issues of power and inequality which we deal with in Chapters 2 and 7. 
There is no separate glossary of terms. We define each new concept as simply as possible when we introduce it. If you want to know more about each idea, use a dictionary or encyclopaedia of sociology. Treat this as a workbook, with ideas, observations and exercises of relevance to practice. It is not intended as a comprehensive sociology textbook. There are many good basic sociology texts which you could use to supplement the work you do in response to our suggestions. Look at the further reading sections at the end of each chapter if you wish to follow up on any ideas.

We believe that reading and learning are best done actively. You should always have in mind your own sense of relevance why you are reading this book, why you are studying this subject, what knowledge or information you hope to gain, how you can use this knowledge in your practice, what problems you hope to solve.

\section{Exercise}

Before starting this book try writing a brief description of how you see your future professional care work. Write about the tasks you anticipate doing, where you will be working, the sort of behaviour you engage in or expect to engage in, and how you expect to feel. Write honestly, since this material is the basic resource with which you relate to this book.

There are Exercises and Key Questions in boxes, just like the one above, which we ask you to do to encourage you to develop these ideas further. They are designed to keep you intellectually active as you read, to encourage reflection and to build your skills in sociological analysis. Please do not skip over these boxes. Put the book down and write the answers to the questions. Such writing will form the basis of what you learn and will inform your future practice.

Similarly, relate other reading and writing to the ideas which we raise. Take note of popular ideas about health and illness that you come across on television or in the newspapers. Keep a cuttings file of interesting articles, or letters to the newspaper. Sociology can then be used to show how your clients' and your 
own imagery about health care is generated, and to analyse how appropriate that imagery is and how it might change.

The best way to learn from sociology is to treat it as an intellectual adventure, a voyage involving discovery, thought, dialogue and imagination. Enjoy the trip. 


\section{Acknowledgements}

We would like to thank all our students and health care professional colleagues, past and present, who have tried out the exercises contained here. We have made amendments based on their comments. The guidance and patience shown by Jo Campling and Catherine Gray at Macmillan are sincerely appreciated. We would particularly like to acknowledge the research assistance of Carol Iphofen; in addition, her reading and commentary on drafts immensely improved the lucidity of what we wanted to say. 